\title{
Volcanic Impacts on Climate and Society working group
}

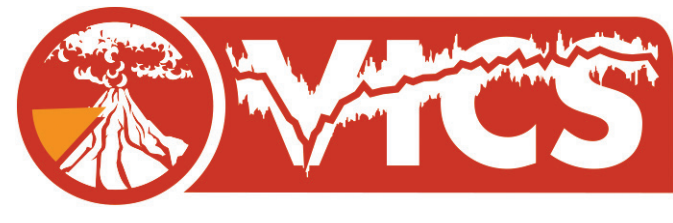

Matthew Toohey', M. Sigl², F. Ludlow ${ }^{3}$, A. N. LeGrande ${ }^{4}$ and K. J. Anchukaitis ${ }^{5}$

Volcanic eruptions are an awe-inspiring example of a natural driver of environmental change. At the local scale, erupted lava, ash and gases can have a drastic impact on the environment, with sometimes severe impacts on ecosystems, human health and economies. Global scale impacts can be produced by major volcanic eruptions, like those of Mt. Pinatubo (1991), or Tambora (1815). Such large-scale effects are due primarily to the injection of sulfur into the stratosphere, resulting in the formation of sulfate aerosols. The primary impact of these aerosols is a decrease in global temperature; however, the aerosols can also affect atmospheric circulation and precipitation patterns, leading to complex regional-scale climate impacts. Information on the climate anomalies resulting from volcanic eruptions in the Earth's past therefore provides important insights for understanding the global and regional climate responses to external forcing agents. This in turn informs predictions of future climate change, such as that due to projected increases in anthropogenic greenhouse gases. Volcanically induced climate changes also provide valuable test cases for understanding the impact of climate variability on society.

A wealth of information is available from modern observations of recent volcanic eruptions, however, the number of such events is relatively small. To broaden our understanding of the impacts of eruptions, we rely on other sources, including geophysical records (e.g. tephra layers, ice cores, and climate proxies such as tree rings), as well as archeological and documentary evidence (Ludlow et al. 2013). While there have been great strides forward over recent decades in understanding the role of volcanic eruptions in climate, important open questions remain, and a wide range of interdisciplinary research on this theme is currently underway globally (see PAGES Magazine 23(2), LeGrande and Anchukaitis 2015).

The Volcanic Impacts on Climate and Society (VICS) working group will provide a forum for information exchange between the diverse research communities interested in volcanic eruptions and climate. VICS has three overarching scientific aims:

(1) Improve volcanic radiative forcing reconstructions. VICS will support the reconstruction of next-generation volcanic forcing datasets - focusing first on the past 2000 years, and eventually the full Holocene - and facilitate their use within modeling efforts such as the Paleo-Modelling Intercomparison Project (PMIP). Progress will incorporate improved knowledge of: volcanic sulfate deposition to Antarctica and Greenland (Sigl et al. 2014 2015), stratospheric transport and deposition of sulfate (Toohey et al. 2013), and the microphysical evolution of aerosols.

(2) Improve understanding of volcanically-induced climate variability. Climate models, proxy-based climate reconstructions and instrumental data don't always agree on the climate impact of major historic eruptions.

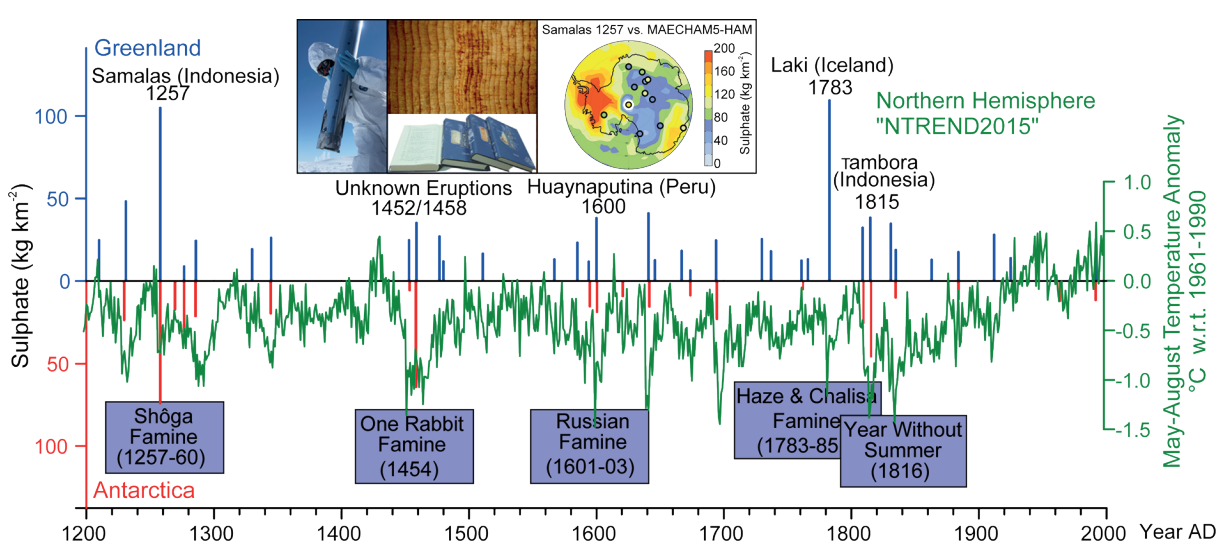

Figure 1: Enhanced atmospheric sulfate burden in the aftermath of large volcanic eruptions as reconstructed from ice cores in Greenland and Antarctica (Sigl et al. 2014, 2015) caused severe summer cooling in the northern hemisphere (Wilson et al. 2016), often associated with crop failures and famines (Puma et al. 2015). Inset suggests archives and tools that can be employed to advance our understanding of the volcanic impact on climate and societies.
VICS will support efforts to reconcile different sources of information, fostering collaboration between the proxy, cryosphere, and climate modeling communities; for example, concerning the validation of climate-model simulations. Special emphasis will be placed on the regional and seasonal character of volcanic climate responses and proxy records, the robustness of decadal-scale responses, dynamical responses linked to atmospheric circulation, the role of different boundary conditions (e.g. season and ENSO state), and the roles of eruption frequency versus magnitude.

(3) Improve understanding of societal impacts of volcanic eruptions. VICS will encourage studies into how major eruptions have impacted societies in the past, based on examination of historical, archeological and paleoecological records, and will also aim to develop tools to better frame climate-model results in terms of societal impacts. Such tools will be helpful in predicting societal impacts of major near-future eruptions; for example, there are major uncertainties concerning how a Pinatubo or larger Tamboramagnitude eruption might impact modern economies.

For more information visit the VICS website (www.pastglobalchanges.org/ini/wg/vics/ intro), where you can also subscribe to the VICS mailing list.

\section{AFFILIATIONS}

'GEOMAR Helmholtz Centre for Ocean Research Kiel, Germany

Paul Scherrer Institute, Villingen, Switzerland ${ }^{3}$ Trinity College Dublin, Ireland

${ }^{4}$ NASA Goddard Institute for Space Studies, New York USA

${ }^{5}$ School of Geography and Development and Laboratory of Tree-ring Research, University of Arizona, Tucson, USA

\section{CONTACT}

Matthew Toohey: mtoohey@geomar.de

\section{REFERENCES}

LeGrande AN, Anchukaits KJ (2015) PAGES Mag 23(2)

Ludlow F et al. (2013) Env Res Lett 8,

doi:10.1088/1748-9326/8/2/024035

Puma MJ et al. (2015) PAGES Mag 23: 66-67

Sigl M et al. (2014) Nature Clim Change 4: 693-697

Sigl M et al. (2015) Nature 523: 543-549

Toohey M et al. (2013) J Geophys Res 118: 4788-4800

Wilson R et al. (2016) Quat Sci Rev 134: 1-18 